\title{
Расчётная модель оптических характеристик соединения AlGaAs для контроля параметров QWIP-структур
}

\author{
М.С. Кораблин ${ }^{1,2}$, В.Е. Гончаров ${ }^{1,3}$, А.В. Никонов ${ }^{2}$ \\ ${ }^{1}$ АО «НПО «Орион», Москва, 111538, ул. Косинская, 9 \\ ${ }^{2}$ МФТИ (НИУ), Долгопрудный, 141701, Институтский пер., 9 \\ ${ }^{3}$ МИРЭА - Российский технологический университет, Москва, 119454, проспект Вернадского, 78 \\ тел:+7 (916) 333-4011, эл. почта: ech@li.ru
}

DOI 10.34077/RCSP2021-120

В технологии изготовления гетероэпитаксиальных структур с множественными квантовыми ямами (QWIP-структур), применяемых для создания матричных фотоприемных устройств среднего и дальнего ИК-диапазона, существенную роль играет прецизионный контроль свойств фоточувствительных материалов [1]. Критически важными контролируемыми характеристиками являются распределение коэффициентов пропускания и отражения структуры по длинам волн излучения. В связи с топологической сложностью QWIP-структур на основе гетеропары $\mathrm{AlGaAs} / \mathrm{GaAs}$ (количество и наноразмерная толщина эпитаксиальных слоев в активной области) актуальной задачей, стоящей перед разработчиками, является реализация расчётных методов, позволяющих как прогнозировать параметры структур с высокой точностью, так и предоставлять необходимые данные для обеспечения технологического процесса эпитаксиального роста.

В проведенном исследовании разработаны расчётные модели диэлектрической проницаемости, показателя преломления, коэффициента поглощения тройного соединения AlGaAs на широком диапазоне состава соединения, а также бинарных соединений GaAs. Дифференциация по составу проводилась посредством применения кубического приближения метода интерполяции Вегарда. Расчётные значения диэлектрической проницаемости рассчитаны из интегральных уравнений Крамерса-Кронига с учетом переходов через Г-, L-, X-долины и непрямых переходов в зоне Бриллюэна в приближении модели кристаллической структуры сфалерита [2]. Выведены расчетные формулы показателя преломления и коэффициента поглощения исследуемых материалов из действительной и мнимой частей комплексной диэлектрической проницаемости, что позволило построить их графики зависимости как от состава материала, так и от длины волны излучения при различных значениях состава. Проведенная апробация полученных результатов по экспериментальным данным сторонних исследователей [3-4] показала корректность расчетной модели, а также возможность рассчитывать значения оптических характеристик с повышенной точностью.

Проведен расчет температурной зависимости оптических характеристик для соединения AlGaAs. Результаты показали, что при изменении температуры, при которой проводились измерения, от нормальных климатических условий $(300 \mathrm{~K})$ до рабочих значений $(77 \mathrm{~K})$ значения оптических характеристик отклонялись на величину порядка 1-3\% относительно НКУ.

Перспективным продолжением данного теоретического исследования является применение полученных результатов для построения расчетных моделей коэффициентов пропускания и отражения многослойных гетероэпитаксиальных структур на основе гетеропары $\mathrm{AlGaAs} / \mathrm{GaAs}$, благодаря чему появится возможность решения как прямой задачи по прогнозированию оптических свойств многослойных гетероэпитаксиальных структур по известной топологии слоистой структуры (количество, порядок, составы и толщины слоев), так и обратной задачи по расчету параметров слоёв, входящих в состав гетероэпитаксиальной структуры, по измеренным спектрам пропускания и отражения. Кроме того, тем самым будет обеспечена возможность разработки экспресс-метода прогнозирования параметров и оптических характеристик не только QWIP-структур, но и альтернативных перспективных структур, таких как сверхрешетки 2 рода и бариодные структуры, используемые в составе высокотемпературных (100-150 К) фотоприемных устройств, являющихся одним из магистральных направлений разработки в современной фотоэлектронике.

\section{Лuтература}

[1] К.О. Болтарь, И.Д. Бурлаков и др. // Прикладная физика. 2016. № 6. С. 37-41.

[2] Р.В. Давлетшин, А.В. Никонов и др. // Успехи прикладной физики. 2019. Т. 7. № 6. С. 571-577.

[3] T. Skauli, P. S. Kuo et al. // J. Appl. Phys. 2003. N 94. P. 6447-6455.

[4] S. Adachi // J. Appl. Phys. 1989. N 66. P. 6030-6040. 